\title{
Activity patterns, time use, and travel of millennials: a generation in transition?
}

\section{Venu M. Garikapati, Ram M. Pendyala, Eric A. Morris, Patricia L. Mokhtarian \& Noreen McDonald}

To cite this article: Venu M. Garikapati, Ram M. Pendyala, Eric A. Morris, Patricia L. Mokhtarian \& Noreen McDonald (2016) Activity patterns, time use, and travel of millennials: a generation in transition?, Transport Reviews, 36:5, 558-584, DOI: 10.1080/01441647.2016.1197337

To link to this article: http://dx.doi.org/10.1080/01441647.2016.1197337

\section{曲 Published online: 28 Jun 2016.}

Submit your article to this journal

山ll Article views: 216

View related articles $\longleftarrow$

View Crossmark data $\nearrow$ 


\title{
Activity patterns, time use, and travel of millennials: a generation in transition?
}

\author{
Venu M. Garikapati ${ }^{\mathrm{a}}$ (D), Ram M. Pendyala ${ }^{\mathrm{a}}$ (D), Eric A. Morris ${ }^{\mathrm{b}}$ (D), \\ Patricia L. Mokhtarian ${ }^{\mathrm{a}}$ (i) and Noreen McDonald ${ }^{\mathrm{C}}$ \\ ${ }^{a}$ School of Civil and Environmental Engineering, Georgia Institute of Technology, Atlanta, GA, USA; \\ ${ }^{\mathrm{b}}$ Department of Planning, Development, and Preservation, Clemson University, Clemson, SC, USA; \\ 'Department of City and Regional Planning, University of North Carolina at Chapel Hill, Chapel Hill, NC, USA
}

\begin{abstract}
Millennials, defined in this study as those born between 1979 and 2000, became the largest population segment in the United States in 2015. Compared to recent previous generations, they have been found to travel less, own fewer cars, have lower driver's licensure rates, and use alternative modes more. But to what extent will these differences in behaviour persist as millennials move through various phases of the lifecycle? To address this question, this paper presents the results of a longitudinal analysis of the 2003-2013 American Time Use Survey data series. In early adulthood, younger millennials (born 1988-1994) are found to spend significantly more time in-home than older millennials (born 1979-1985), which indicates that there are substantial differences in activity-time use patterns across generations in early adulthood. Older millennials are, however, showing activity-time use patterns similar to their prior generation counterparts as they age, although some differences - particularly in time spent as a car driver - persist. Millennials appear to exhibit a lag in adopting the activity patterns of predecessor generations due to delayed lifecycle milestones (e.g. completing their education, getting jobs, marrying, and having children) and lingering effects of the economic recession, suggesting that travel demand will resume growth in the future.
\end{abstract}

\section{ARTICLE HISTORY}

Received 4 September 2015

Accepted 31 May 2016

\section{KEYWORDS}

Millennials; activity-time use patterns; travel behaviour; cohort analysis; age effects; trend analysis; longitudinal analysis; lifecycle stages

\section{Introduction}

Many a headline posits that the millennial generation is redefining every aspect of the social, political, demographic, technological, and economic fabric of the United States. In 2015, the millennial generation (or Gen Y), which is defined in this paper as those born between 1979 and 2000, became the largest population segment in the United States, outnumbering each of the other generations comprising the US population (Pew Research Center, 2015) - including, the Silent Generation (born 1928-1945), the Baby Boomers (born 1946-1964), and Generation X (born 1965-1978). With their increasing presence and clout in the marketplace and workplace, it is not surprising that considerable 
attention is being paid to millennials' priorities, lifestyle preferences, environmental values, technology adoption, activity, travel, and housing choices. Millennials are being touted as the frugal generation (O'Connell, 2015) with respect to their spending habits, and the "go-nowhere" generation (Buchholz \& Buchholz, 2012) in their activity and travel patterns.

In view of the unique traits exhibited by millennials thus far, transportation planning professionals are grappling with understanding how travel demand will evolve in the future as millennials age, and the consequent implications for transport infrastructure investment and policy formulation. There is therefore considerable interest in quantifying and tracking the activity, travel, and time use patterns of millennials. It is well documented that millennials, largely born and raised in an era of ubiquitous technology ("digital natives"), are exhibiting mobility patterns that are different from those of their predecessor cohorts (Dutzik, Inglis, \& Baxandall, 2014). They have been found to exhibit lower rates of driver's licensure (Delbosc \& Currie, 2013; Sivak \& Schoettle, 2011, 2012), have lower rates of car ownership, and undertake fewer trips and travel fewer miles and minutes on a daily basis (McDonald, 2015; Polzin, Chu, \& Godfrey, 2014).

The question of interest is whether these differences will persist or fade as millennials age, and the resulting implications for the future of travel demand. Previous research has not been able to shed light on the effects of ageing on the activity and travel trends of millennials. Although differences are observed when comparing young adults of today with the young adults of past generations (McDonald, 2015), there is little evidence on whether the differences will persist into the future. Lyons (2015) suggests that they will, with the advent of social media and technology-based services contributing to lasting differences (Davis, Dutzik, \& Baxandall, 2012; van Wee, 2015). But with myriad reports and surveys on the behavioural choices and lifestyle preferences of millennials, it has become increasingly difficult to separate hype from reality and fully assess how millennial activity and travel demand are likely to evolve in the future.

In light of the dearth of longitudinal studies on the activity and time use patterns of millennials that effectively isolate cohort and ageing effects, this paper aims to present an in-depth analysis of trends in activity and time use for different age groups and generations. The intent of the paper is to unravel the progression of activity and time use patterns for millennials as they age, and compare their trends with those of the immediate preceding generation (Generation X). Unlike previous research that used household travel survey data (e.g. McDonald, 2015), the analysis in this paper is performed using the American Time Use Survey (ATUS) 2003-2013 data series with a view to deriving deeper insights into activity engagement and time use differences across generational cohorts. As the 11-year span covered by the data includes the period of the worst recession in recent memory, the longitudinal information in the multi-year data set can not only be used to see how activity-travel patterns have changed over time for specific age groups and cohorts, but also how the recession may have played a role in shaping these trends. Several questions can be answered through such a trend analysis. How different are the 18-24-year-old individuals of 2003-2004 (older millennials born 1979-1985) from the 18-24-year-old individuals of 2012-2013 (younger millennials born 1988-1994)? How have the travel and activity patterns of older millennials changed as they have aged? How do older millennials compare to the previous generation (Generation $X$ ) at the same age? Through a longitudinal analysis that explicitly controls for ageing effects and 
cohort effects, this paper aims to shed considerable light on how activity and time use patterns differ across generations and differ in the ways they have changed over time.

The scope of this paper is limited to the analysis of trends within the 11-year time span of the ATUS (2003-2013) data series. As such, it is not possible to unravel longer-term trends in activity and time use patterns; thus while the analysis is able to provide initial insights into changes in millennial activity-time patterns over time, only future waves of the ATUS data can truly provide confirmatory evidence on the patterns of change in millennial activity-time use trends as they age into advanced lifecycle stages. The oldest millennials in the data set (born in 1979) are 24 years of age in 2003 and 34 years of age in 2013; as a result, activity-time use patterns of millennials are not observed into more mature lifecycle stages. Nevertheless, the measurement of changes observed in the 11-year span of data can provide key insights into the trajectory of activity-time use patterns. Another important caveat is that the analysis in this paper effectively controls for ageing effects and cohort effects, but there are likely to be important period effects that are also at play in shaping activity-time use patterns. While the 11-year time span of the ATUS data series is short enough that there are unlikely to be any fundamental structural differences in societal form and function, the severe recession, the rapid evolution of technology, and the growth in the sharing economy and social media platforms experienced within this time span are likely to contribute to period effects. The analysis in this paper is unable to isolate such period effects, but differences in activity-time use patterns and trends are discussed in the context of potential period effects that may be at play. In order to further mitigate the potential role of period effects, the analysis in this paper is limited to comparing adjacent generational cohorts (Millennials and Generation $\mathrm{X}$ ) as opposed to comparing generations that are more temporally separated from one another (e.g. Millennials and Baby Boomers).

The remainder of this paper is organised as follows. The next section provides an overview of some of the conflicting literature on millennials. The third section describes the data set used in this study and the overall trends that are present in the data. The fourth and fifth sections of the paper offer descriptive trend analyses of the data with a focus on cohort effects, ageing effects, and differences across generations at specific age brackets. A discussion on the findings and concluding remarks are in the sixth and final section of the paper.

\section{Conflicting reports on the millennials}

Millennials are held to be redefining the American dream, no longer valuing home ownership, car ownership, and a steady job, but rather focusing on a purpose-driven life to impact society and create a better tomorrow (Guay, 2015). Some suggest that millennials no longer value ownership in an era that is seeing the burgeoning sharing economy (Lutz, 2014; O'Connell, 2015). Compared to previous generations, they are more likely to prefer on-demand mobility services such as Uber and Lyft to traditional car ownership, rent accommodation through AirBnB, and stream their music through Spotify. Millennials born and brought up in an era of ubiquitous technology and connectivity may be substituting driving (and owning cars) and out-of-home activity participation with in-home virtual activities. Indeed, recent research (e.g. Le Vine, Latinopoulos, \& Polak, 2014) suggests that more time spent online is associated with less driving. 
There is a steady stream of editorials and blogs discussing how and why millennials are driving less (Jaffe, 2015), shunning cars (Badger, 2014), and utilising alternative modes of transportation in greater numbers than prior generations. They exhibit lower levels of car ownership, driver's licensure, and mobility (in terms of travel time expenditures, trip rates, and vehicle miles of travel (VMT)) when compared with previous generations (Lyons, 2015; McDonald, 2015; Polzin et al., 2014). Stokes (2012) provides further evidence of falling licensure rates among younger cohorts in Germany, France, and Britain. Similarly, Le Vine and Jones (2012) report that individuals in their 20s (who largely constitute the millennial generation) are driving significantly less than their earlier cohorts at the same age.

Some surveys indicate that millennials are redefining the urban landscape as they tend to live in dense urban environments that are less car-dependent (Nielsen, 2014). Twothirds of millennials are renters, and they are more likely to be living with roommates or family members than alone. Based on an exploratory analysis of the Great Britain National Travel Survey data, Stokes (2013) reports that demographic shifts and changes in residential location preferences will play a major role in shaping future levels of car access and use. Millennials are delaying marriage and waiting to have children, perhaps in part due to financial woes brought about by the great recession (Lamberti, 2015). Indeed, it has been found that millennials are more likely to be in school (Taylor et al., 2012; Thompson, 2012) and less likely to be employed, married, or parents (Furstenberg, 2010; Pew Research Center, 2015) than prior generations were at the same ages. Others have written that millennials are adventurous, increasingly seeking overseas travel experiences (Machado, 2014), possibly at the expense of local day-to-day travel.

While many of the headlines suggest the dawn of a new era with the emergence of the millennial generation, several key questions remain unanswered. There are the beginnings of a recognition that lifestyles and patterns of behaviour may not necessarily be all that different in the future as millennials age. The zipcar annual millennial survey suggests that being a "millennial" is related to where an individual lives (the contextual situation) as opposed to when the individual was born (Wester, 2015; zipcar, 2015). It appears that millennials may not be all that different from prior generations in terms of their motivations and desires in the workplace (Biro, 2014). A consistent finding among studies of millennials is that only $12-14 \%$ live in America's downtowns (Leanne \& Brett, 2015); while this fraction is larger than that of previous generations, the difference is not substantial enough to transform the urban landscape. Moreover, Walker (2015) notes that: "it turns out that many millennials were not ever planning on settling in cities for good - they were just putting off the move to the suburbs for a few more years". Rossenfeld (2015) suggests that millennials will demand "urban burbs" - suburban locations that offer the amenities and benefits of city living without the associated challenges. As the economy improves and millennials move through various phases of their lives, their housing preferences may mirror those of previous generations; the demand for new single-family homes is likely to increase as millennials enter their 30s (Logan, 2014). A recent survey by the National Association of Home Builders indicates that two-thirds of millennials want to live in the suburbs, $24 \%$ want to live in rural areas, and only $10 \%$ want to live in urban city centres (Hudson, 2015).

A longitudinal analysis of activity, travel, and time use patterns has the potential to provide considerable insights into how millennials are evolving with respect to their behavioural choices. In the transport arena, such analyses have been largely limited to 
comparing behaviours of specific age groups across cross-sections of national or other household travel surveys (e.g. McDonald, 2015; Polzin et al., 2014). While such comparisons offer interesting insights into differences in mobility variables, particularly over longer time spans, they do not adequately control for ageing and cohort effects and do not provide detailed information about the substitution of out-of-home activities with in-home activities. The ATUS data set, although covering a shorter 11-year span and somewhat limited with respect to its measurement of mobility variables, offers a rich basis to conduct ageperiod-cohort analysis of activity-time use patterns for different generations. The detailed time use data offer information about both out-of-home and in-home activity engagement, thus facilitating a determination of how the millennial generation differs from Generation $\mathrm{X}$ in terms of its activity-travel behaviour and time use. An exploration of ageing effects using the longitudinal data series will help reveal whether activity-travel and time use patterns of millennials are remaining steady, or converging/diverging in comparison to patterns observed for Generation X.

\section{Data description and overall trends in time use}

The data for this study is derived from the 2003-2013 ATUS data series. The survey is administered annually to a representative sample of individuals aged 15 years and above to obtain detailed information about household and person-level socio-economic and demographic characteristics, and out-of-home and in-home activity engagement and time use patterns for a one-day study period. In this research effort, data were combined for three pairs of neighbouring years, namely, 2003-2004, 2007-2008, and 2012-2013, to perform a trend analysis. These three snapshots were chosen for analysis to maximise the range in the period covered (the entire 11-year period) and to capture the effects of the recession, if any, that should be reflected in the 2007-2008 snapshot (with possible lingering effects into 2012-2013). Adjacent year data were combined to ensure that adequate sample sizes were available for the age and cohort subgroups of interest. Although the data include information for individuals 15 years old and above, the analysis in this paper is limited to adults (18 years and above) because minors are largely dependent on adults for activity and travel engagement. For this reason, only millennials born between 1979 and 1995 were included in the analysis sample for this paper (those born in 1995 are 18 years of age in 2013). In order to reduce the potential influence of period effects, comparisons of activity-travel and time use patterns were performed between millennials and the immediate prior generation, namely, Generation X. The sample is uniformly distributed across all days of the week in each survey year, thus allowing comparisons across years without the prevalence of day-of-week effects. All of the analysis was performed on weighted samples; unweighted sample sizes are furnished in the tables for informational purposes.

Table 1 summarises the characteristics of the entire sample at the three snapshots considered in this paper. As expected, the population is becoming increasingly diverse (albeit slowly) with a slight drop in the White race share accompanied by a rise in share of Asian and Hispanic subpopulations. Among individuals who have at least some college education, the percentage of individuals without a college degree is falling while the percentage with a college degree is modestly rising, signifying the growing influence of the millennials who are the most educated generation ever (The Council of Economic 
Table 1. Descriptive statistics for adults 18 years and over (weighted sample).

\begin{tabular}{|c|c|c|c|c|}
\hline \multirow[b]{2}{*}{ Variable } & \multirow[b]{2}{*}{ Category } & \multicolumn{3}{|c|}{ Survey pool } \\
\hline & & 2003-2004 & 2007-2008 & 2012-2013 \\
\hline \multirow[t]{4}{*}{ Race } & White & $83.8 \%$ & $82.9 \%$ & $81.6 \%$ \\
\hline & Black & $11.3 \%$ & $11.5 \%$ & $12.0 \%$ \\
\hline & Asian & $2.8 \%$ & $3.2 \%$ & $4.3 \%$ \\
\hline & All other & $2.1 \%$ & $2.4 \%$ & $2.1 \%$ \\
\hline Hispanic & Yes & $12.3 \%$ & $13.3 \%$ & $14.7 \%$ \\
\hline \multirow[t]{4}{*}{ Highest level of education ${ }^{a}$} & Some college - no degree & $35.2 \%$ & $33.2 \%$ & $31.1 \%$ \\
\hline & Associate degree & $14.8 \%$ & $15.5 \%$ & $15.4 \%$ \\
\hline & Bachelor's degree & $32.8 \%$ & $33.4 \%$ & $34.2 \%$ \\
\hline & Master's degree or higher & $17.2 \%$ & $17.9 \%$ & $19.3 \%$ \\
\hline \multirow[t]{3}{*}{ Labour force status } & Employed & $66.3 \%$ & $67.7 \%$ & $63.1 \%$ \\
\hline & Unemployed & $4.4 \%$ & $4.1 \%$ & $5.5 \%$ \\
\hline & Not in labour force & $29.3 \%$ & $28.2 \%$ & $31.4 \%$ \\
\hline \multirow[t]{2}{*}{ Income $e^{b, c}$} & $<\$ 25,000$ & $46.0 \%$ & $39.9 \%$ & $37.3 \%$ \\
\hline & $>\$ 50,000$ & $19.7 \%$ & $25.4 \%$ & $29.7 \%$ \\
\hline Spouse presence & Yes & $63.3 \%$ & $61.3 \%$ & $59.4 \%$ \\
\hline Child presence & Yes & $39.2 \%$ & $37.9 \%$ & $35.9 \%$ \\
\hline Home ownership & Owned/bought by household & $75.7 \%$ & $75.2 \%$ & $71.6 \%$ \\
\hline \multirow[t]{6}{*}{ Time spent ... (minutes) } & Alone & 289 & 292 & 293 \\
\hline & With household members & 265 & 261 & 260 \\
\hline & With spouse only & 105 & 104 & 102 \\
\hline & With spouse only ${ }^{d}$ & 166 & 169 & 171 \\
\hline & With spouse (others present) & 163 & 160 & 157 \\
\hline & With friends & 51 & 46 & 50 \\
\hline Sample size (unweighted) & & 33077 & 23714 & 22928 \\
\hline
\end{tabular}

${ }^{a}$ Computed based on individuals with at least some college education.

${ }^{\mathrm{b}}$ Computed based on valid cases.

${ }^{\mathrm{c}}$ Not inflation-adjusted.

${ }^{\mathrm{d}}$ Computed only for individuals with a spouse.

Advisors, 2014). The percentage employed shows a dip over time, possibly reflecting the tepid recovery from the recession and the ageing of the baby boomers who are increasingly joining the ranks of the retired. The percentage who have spouses and children shows a steady decline, likely reflecting delayed marriage and child-bearing among millennials, and the empty-nest lifestyles of baby boomer households.

The average total time (per day) that respondents spend alone shows a slight increase over time, and this trend is accompanied by a decrease in time spent with household members. The time spent with spouse shows a decreasing trend for the population as a whole; this trend is explained by the lower share of households with spouses over time as millennials experience lifecycle milestones (such as marriage) later in life than previous generations, and as they constitute an increasing share of the adult population in the United States. However, when only the subsample of households that includes a spouse is considered, the trend is reversed (albeit modestly) with a gradual increase in time spent with spouse across the survey years. This increase is consistent with the fact that the share of households with children present is decreasing over time. This decreasing trend stems from two possible sources: first, increasing numbers of baby boomers are joining the ranks of the retired and become empty nest households, and second, millennials, who constitute an increasing share of the adult population over time, are delaying having children.

Table 2 presents a longitudinal exploration of mean time use patterns considering specific age groups at different survey snapshots. The time use patterns of 18-24-year-olds, 
Table 2. Activity-time use trends for different age groups (average minutes per day).

\begin{tabular}{|c|c|c|c|c|c|c|c|c|c|c|}
\hline \multirow[b]{2}{*}{ Activity } & \multirow[b]{2}{*}{ Place } & \multicolumn{3}{|c|}{ Age (18-24) } & \multicolumn{3}{|c|}{ Age (25-34) } & \multicolumn{3}{|c|}{ Age (35-54) } \\
\hline & & 2003-2004 & 2007-2008 & 2012-2013 & 2003-2004 & 2007-2008 & 2012-2013 & 2003-2004 & $2007-2008$ & 2012-2013 \\
\hline Personal care in-home only & Total & 44 & 46 & 46 & 42 & 43 & 42 & 46 & 45 & 45 \\
\hline Sleep in-home only & Total & 543 & 540 & 556 & 510 & 513 & 522 & 494 & 498 & 509 \\
\hline \multirow[t]{3}{*}{ Household activities } & In-Home & 53 & 51 & 48 & 87 & 86 & 81 & 113 & 111 & 105 \\
\hline & Out-of-Home & 7 & 9 & 6 & 7 & 6 & 8 & 6 & 6 & 7 \\
\hline & Total & 60 & 60 & 54 & 94 & 93 & 89 & 120 & 117 & 112 \\
\hline \multirow[t]{3}{*}{ Caring for and helping household members } & In-Home & 17 & 16 & 19 & 51 & 49 & 46 & 28 & 27 & 28 \\
\hline & Out-of-Home & 3 & 4 & 3 & 9 & 9 & 9 & 8 & 8 & 9 \\
\hline & Total & 21 & 20 & 22 & 60 & 58 & 55 & 36 & 36 & 37 \\
\hline \multirow[t]{3}{*}{ Caring for and helping non-household members } & In-Home & 3 & 1 & 1 & 1 & 1 & 1 & 3 & 3 & 2 \\
\hline & Out-of-Home & 8 & 8 & 5 & 8 & 4 & 4 & 7 & 5 & 5 \\
\hline & Total & 11 & 9 & 6 & 9 & 5 & 5 & 11 & 7 & 7 \\
\hline \multirow[t]{3}{*}{ Work and work-related activities } & In-Home & 6 & 6 & 12 & 16 & 18 & 17 & 21 & 26 & 27 \\
\hline & Out-of-Home & 187 & 218 & 169 & 252 & 257 & 238 & 248 & 249 & 238 \\
\hline & Total & 193 & 223 & 181 & 268 & 275 & 255 & 269 & 275 & 266 \\
\hline \multirow[t]{3}{*}{ Education } & In-Home & 21 & 26 & 24 & 6 & 7 & 11 & 3 & 3 & 4 \\
\hline & Out-of-Home & 48 & 42 & 43 & 9 & 7 & 12 & 3 & 2 & 2 \\
\hline & Total & 69 & 68 & 67 & 15 & 14 & 23 & 6 & 5 & 6 \\
\hline \multirow[t]{3}{*}{ Consumer purchases } & In-Home & 1 & 1 & 0 & 0 & 1 & 1 & 1 & 1 & 1 \\
\hline & Out-of-Home & 23 & 22 & 18 & 25 & 22 & 22 & 24 & 23 & 22 \\
\hline & Total & 24 & 23 & 18 & 25 & 22 & 23 & 25 & 24 & 22 \\
\hline \multirow[t]{3}{*}{ Eating and drinking } & In-Home & 26 & 27 & 30 & 33 & 33 & 36 & 37 & 38 & 39 \\
\hline & Out-of-Home & 29 & 32 & 29 & 31 & 30 & 30 & 27 & 27 & 25 \\
\hline & Total & 54 & 59 & 60 & 63 & 63 & 66 & 65 & 65 & 64 \\
\hline \multirow[t]{3}{*}{ Socialising, relaxing, and leisure } & In-Home & 190 & 171 & 206 & 176 & 173 & 180 & 195 & 196 & 201 \\
\hline & Out-of-Home & 87 & 81 & 75 & 52 & 53 & 50 & 40 & 39 & 39 \\
\hline & Total & 278 & 253 & 281 & 228 & 226 & 230 & 235 & 236 & 241 \\
\hline \multirow[t]{3}{*}{ Sports, exercise, and recreation } & In-Home & 3 & 2 & 4 & 2 & 2 & 2 & 2 & 3 & 3 \\
\hline & Out-of-Home & 23 & 25 & 25 & 16 & 14 & 16 & 14 & 15 & 14 \\
\hline & Total & 25 & 28 & 29 & 19 & 17 & 18 & 17 & 17 & 16 \\
\hline Travel out-of-home only & Total & 87 & 79 & 76 & 81 & 78 & 77 & 82 & 77 & 77 \\
\hline \multirow[t]{3}{*}{ Other } & In-Home & 10 & 9 & 10 & 6 & 7 & 6 & 9 & 9 & 8 \\
\hline & Out-of-Home & 15 & 14 & 15 & 15 & 15 & 14 & 20 & 19 & 17 \\
\hline & Total & 24 & 23 & 25 & 21 & 22 & 20 & 29 & 28 & 25 \\
\hline
\end{tabular}


Table 2. Continued.

\begin{tabular}{|c|c|c|c|c|c|c|c|c|c|c|}
\hline \multirow[b]{2}{*}{ Activity } & \multirow[b]{2}{*}{ Place } & \multicolumn{3}{|c|}{ Age (18-24) } & \multicolumn{3}{|c|}{ Age (25-34) } & \multicolumn{3}{|c|}{ Age (35-54) } \\
\hline & & 2003-2004 & $2007-2008$ & $2012-2013$ & 2003-2004 & $2007-2008$ & 2012-2013 & 2003-2004 & $2007-2008$ & 2012-2013 \\
\hline \multirow{2}{*}{ Unable to code } & Out-of-Home & 3 & 5 & 13 & 2 & 3 & 5 & 2 & 2 & 4 \\
\hline & Total & 7 & 10 & 19 & 6 & 9 & 14 & 6 & 10 & 12 \\
\hline Sample size (unw & & 2443 & 1571 & 1398 & 5776 & 4102 & 3845 & 14123 & 10057 & 8852 \\
\hline
\end{tabular}

Notes: No out-of-home durations were recorded for personal care and sleep. No in-home duration was recorded for travel. 
25-34-year-olds, and 35-54-year-olds are reported in three different cross-sections for each pair of years. Although this table does not explicitly control for cohort or ageing effects, the trends offer some initial insights into how activity-time allocation patterns are changing over time for different age groups. The table reports both in-home and out-of-home time use for various activity purposes. Personal care and sleep activities do not have any location information recorded and are treated as purely in-home; on the other hand, travel is treated purely as an out-of-home activity. All other activities may have both in-home and out-ofhome activity durations.

In viewing the trends shown in Table 2, it should be noted that different populations are being compared over time, albeit in similar age brackets. For example, the 18-24-year-olds are millennials in all three snapshots, but born in 1979-1985, 1983-1989, and 1988-1994, respectively. Compared to their same-age counterparts in prior survey years, individuals 18-24 years of age in 2012-2013 (who are younger millennials) slept longer, spent less time on household activities, spent less time caring for non-household members, and spent more time pursuing in-home (presumably online) education and less time pursuing out-of-home education. This age group also spent less time at work in 2012-2013, but spent considerably more time working or looking for work in 2007-2008 during the period of the recession.

Those who were 18-24 years of age in 2012-2013 also spent less time on consumer purchases, presumably due to the effects of the severe recession. Socialising and relaxation registered a dramatic drop among 18-24-year-olds during the recession (consistent with the spike in time spent at work or looking for work), but recovered substantially for this age group in 2012-2013. There is some evidence of location substitution in this activity category, as in-home socialising and relaxation shows a sharp increase in 20122013 for 18-24-year-old individuals while out-of-home socialising and relaxation shows a substantial decrease. These trends reflect tighter monetary budgets and at least some substitution of in-home technology-enabled socialisation and relaxation. Of particular interest here, the 18-24-year-olds in 2012-2013 travelled 11 minutes less, on average, than 18-24-year-olds in 2003-2004, which is a large proportional difference given that the total travel is in the neighbourhood of 80 minutes per day. Other activities held steady in duration, while activities that are unable to be coded registered a dramatic increase for the 18-24-year-old age group over time (these include activities performed during multitasking, and activities that respondents refused to disclose, did not know/ remember, or could not explain adequately).

The 25-34-year-old age group comprises purely of older millennials in 2012-2013, and purely of Generation X individuals in 2003-2004, with a mix of the two generations in 2007-2008. Sleep duration, on average, increases for 25-34-year-old individuals, suggesting that millennials devote more time to sleep than Generation X individuals. The duration of household activities drops over time among 25-34-year-olds, but (consistent with their more advanced lifecycle stage) they still spend more time on these activities than 18-24-year-olds do. Unlike 18-24-year-olds, the 25-34-year-olds register a drop over the course of the decade in time allocated to caring for household members, presumably due to the postponement of marriage and child-bearing among this age group (recall that 25-34-year-olds are exclusively millennials in 2012-2013).

Although not as pronounced as that seen for 18-24-year-olds, the other age groups also register an increase in time allocated to work or looking for work in 2007-2008 
(in the midst of the recession) and a drop in 2012-2013. Time spent for education increases on average for 25-34-year-olds, suggesting that older millennials are pursuing education more than their equivalent age counterparts in prior years. All three age groups exhibit increased time socialising and relaxing in the more recent time period of 2012-2013, but the 18-24-year-olds show a substantial decrease in this activity category in 2007-2008, suggesting that the youngest adults were most affected by the recessionary forces. Travel time expenditures show a decreasing trend for all age groups, with the 1824-year-old group showing the largest reduction in average daily travel time expenditure. This is consistent with findings recently documented in the literature (Goodwin \& Van Dender, 2013; Kuhnimhof et al., 2012; Litman, 2006; Millard-Ball \& Schipper, 2011; Sivak, 2013). Although the literature alludes to a potential fundamental transformation in attitudes towards travel that may be contributing to a "peak car/peak travel" phenomenon underlying such trends, it is more likely that the economic recession contributed substantially to this decrease. More recent data (Polzin, 2016) show that, in the United States, aggregate VMT reached new highs in 2015 and even per-capita VMT are beginning to recover to pre-recessionary levels. Similar to the 18-24-year-olds, the other age groups register substantial increases in activities that are unable to be coded, although the magnitudes of increase are lower for 25-34- and 35-54-year-old individuals. It appears that individuals of all ages, and 18-24-year-olds in particular, are increasingly pursuing more complex activity patterns characterised by multitasking and greater use of information and communication technologies (ICT) that are difficult to code.

Overall, it can be seen that there are discernible trends in activity time allocation as the decade progressed. However, barring a few exceptions, the trends are rather similar for the different age groups, which suggests that differences seen among young adults over the course of a decade are not that unusual or inconsistent with changes exhibited by adults in the older age brackets. Of particular interest, time spent travelling dropped substantially for all age groups. This suggests that, although the narrative of falling millennial travel is justified, this trend is likely due in considerable measure to economic, technological, psychological, social, and cultural factors experienced by all age groups. While the young adults show larger differences over time, the general trends are consistent across age groups - providing the first indication that millennials may not be all that different from prior generations.

\section{An examination of ageing effects}

The overview in the previous section offered a summary of trends in the data sets without necessarily controlling for cohort or ageing effects. In order to better isolate trends and identify ageing effects, this section presents a trend analysis for three distinct cohorts: Generation X born 1967-1972 (the older GenX, referred to as GenX1), Generation X born 1973-1978 (the younger GenX, referred to as GenX2), and the Millennials born 1979-1985 (the older millennials). The older GenX group (GenX1) would be in their early 30s in 2003-2004. GenX2 would largely be in their late 20s in 2003-2004 and early 30s in 2012-2013. Millennials born 1979-1985 would be roughly in their early 20s in 2003-2004, in their mid-to-late 20s in 2007-2008, and in their late 20s to early 30s by 2012-2013. Thus, it is possible to compare the evolution of activity-time use patterns of older millennials as they aged. No data are available for the GenX1 group in their early 
20s and mid-/late 20s, and for the GenX2 group in their early 20s, because of the limited span of the ATUS data series.

Before presenting trends in activity-time use patterns for various cohorts, trends in socio-economic and demographic characteristics are examined first. Through an understanding of differences in trends in socio-economic characteristics across generational cohorts, it is possible to identify the socio-economic and demographic phenomena at play that may be contributing to differences in activity-time use patterns. Table 3 presents socio-economic and demographic trends for the three different cohorts considered in this paper.

It can be seen that a greater proportion of millennials constitute single-person households in their 20s and early 30s than is the case for Generation X. A smaller share of millennials have a spouse or live in households with children. It is found that the GenX2 group also exhibits a lower prevalence of spouse and children presence in comparison to the GenX1 group. In other words, lifecycle milestones (e.g. marriage, having children) are progressively getting delayed from one generation to the next (Lamberti, 2015; Martin, Astone, \& Peters, 2014), and these delayed milestone events would naturally contribute to differences in activity-time use trends. The millennial generation is also slightly more diverse than predecessor generations, leading to the presence of cultural factors that contribute, at least in part, to differences in activity-time use trends, driver's licensure rates, vehicle ownership, and mode usage (Blumenberg, 2009). A larger percentage of millennials are also enrolled in college or possess some college education when compared with predecessor generations. The pattern in the table shows that each generation tends to be more educated than the preceding generation. As socio-economic and demographic characteristics are important determinants of activity-travel and time use patterns, differences in such characteristics among groups would be expected to contribute to differences in activity-time use trends.

Figure 1 presents the comparison of time use patterns for different cohorts as they age. The objective here is to examine trends for similarities and differences over time. A oneway analysis of variance (ANOVA) was conducted to test whether the average values are significantly different across cohorts when they are in their late 20s/early 30s. It can be seen from the figure that, barring a few exceptions, as the older millennials age, their daily time allocation is neatly converging to the corresponding values exhibited by GenX2 and GenX1 individuals in their late 20s/early 30s. A noteworthy observation is the very steady convergence of total time spent in-home vs. out-of-home (about 16 and 8 hours, respectively). Work and work-related activities consume about 4.5 hours per day (note that the figures include weekend and holiday days), and personal care activities for all three cohorts amount to just over 40 minutes in duration.

The amount of time spent caring for household members is settling at just over one hour per day. Consistent with the finding that a smaller share of millennials reside in households with a spouse or children in their late 20s/early 30s (as seen in Table 3), this cohort spends comparatively less time caring for household members than GenX individuals; the difference is not, however, statistically significant - indicating a pattern of convergence in time allocation to household member care. Similar convergent trends can be seen for time allocation to socialising and relaxation, eating and drinking, and sports, exercise, and recreation activities. Millennials spend less time caring for non-household members and engaging in other activities in their late 20s/early 30s when compared 
Table 3. Progression of demographic trends for different cohorts.

\begin{tabular}{|c|c|c|c|c|c|}
\hline \multirow[b]{2}{*}{ Variable } & \multirow[b]{2}{*}{ Category } & \multirow[b]{2}{*}{ Cohort (year of birth) } & \multicolumn{3}{|c|}{ Age-stage } \\
\hline & & & Early $20 \mathrm{~s}$ & Mid-/late $20 \mathrm{~s}$ & Late 20 s/early $30 \mathrm{~s}$ \\
\hline \multirow{3}{*}{ Household size } & One & GenX1 (1967-1972) & - & - & $9.1 \%$ \\
\hline & & GenX2 (1973-1978) & - & $10.0 \%$ & $11.3 \%$ \\
\hline & & Millennials (1979-1985) & $5.4 \%$ & $12.8 \%$ & $12.0 \%$ \\
\hline \multirow[t]{3}{*}{ Child presence } & Yes & GenX1 (1967-1972) & - & - & $69.2 \%$ \\
\hline & & GenX2 (1973-1978) & - & $50.1 \%$ & $62.5 \%$ \\
\hline & & Millennials (1979-1985) & $44.3 \%$ & $42.0 \%$ & $54.4 \%$ \\
\hline \multirow[t]{6}{*}{ Spouse presence } & Yes & GenX1 (1967-1972) & - & - & $73.1 \%$ \\
\hline & & GenX2 (1973-1978) & - & $62.8 \%$ & $67.0 \%$ \\
\hline & & Millennials (1979-1985) & $20.2 \%$ & $42.9 \%$ & $61.6 \%$ \\
\hline & White & GenX1 (1967-1972) & - & - & $81.5 \%$ \\
\hline & & GenX2 (1973-1978) & - & $81.2 \%$ & $80.3 \%$ \\
\hline & & Millennials (1979-1985) & $81.5 \%$ & $81.2 \%$ & $78.2 \%$ \\
\hline \multirow[t]{6}{*}{ Race } & Black & GenX1 (1967-1972) & - & - & $11.9 \%$ \\
\hline & & GenX2 (1973-1978) & - & $11.3 \%$ & $12.3 \%$ \\
\hline & & Millennials (1979-1985) & $12.1 \%$ & $11.6 \%$ & $12.9 \%$ \\
\hline & Asian & GenX1 (1967-1972) & - & - & $4.1 \%$ \\
\hline & & GenX2 (1973-1978) & - & $4.8 \%$ & $5.5 \%$ \\
\hline & & Millennials (1979-1985) & $3.7 \%$ & $4.0 \%$ & $6.3 \%$ \\
\hline \multirow[t]{3}{*}{ Currently enrolled in college } & Yes & GenX1 (1967-1972) & - & - & $7.5 \%$ \\
\hline & & GenX2 (1973-1978) & - & $15.3 \%$ & $9.6 \%$ \\
\hline & & Millennials (1979-1985) & $45.5 \%$ & $17.5 \%$ & $10.4 \%$ \\
\hline \multirow[t]{3}{*}{ Highest level of education } & Some college or higher & GenX1 (1967-1972) & - & - & $60.3 \%$ \\
\hline & & GenX2 (1973-1978) & - & $57.8 \%$ & $61.7 \%$ \\
\hline & & Millennials (1979-1985) & $45.5 \%$ & $59.4 \%$ & $66.8 \%$ \\
\hline \multirow[t]{3}{*}{ Labour force status } & Employed & GenX1 (1967-1972) & - & - & $81.6 \%$ \\
\hline & & GenX2 (1973-1978) & - & $80.4 \%$ & $81.1 \%$ \\
\hline & & Millennials (1979-1985) & $69.1 \%$ & $82.8 \%$ & $79.4 \%$ \\
\hline \multirow[t]{3}{*}{ Sample size (unweighted) } & & GenX1 (1967-1972) & - & - & 4219 \\
\hline & & GenX2 (1973-1978) & - & 2974 & 2711 \\
\hline & & Millennials (1979-1985) & 2443 & 2102 & 2854 \\
\hline
\end{tabular}



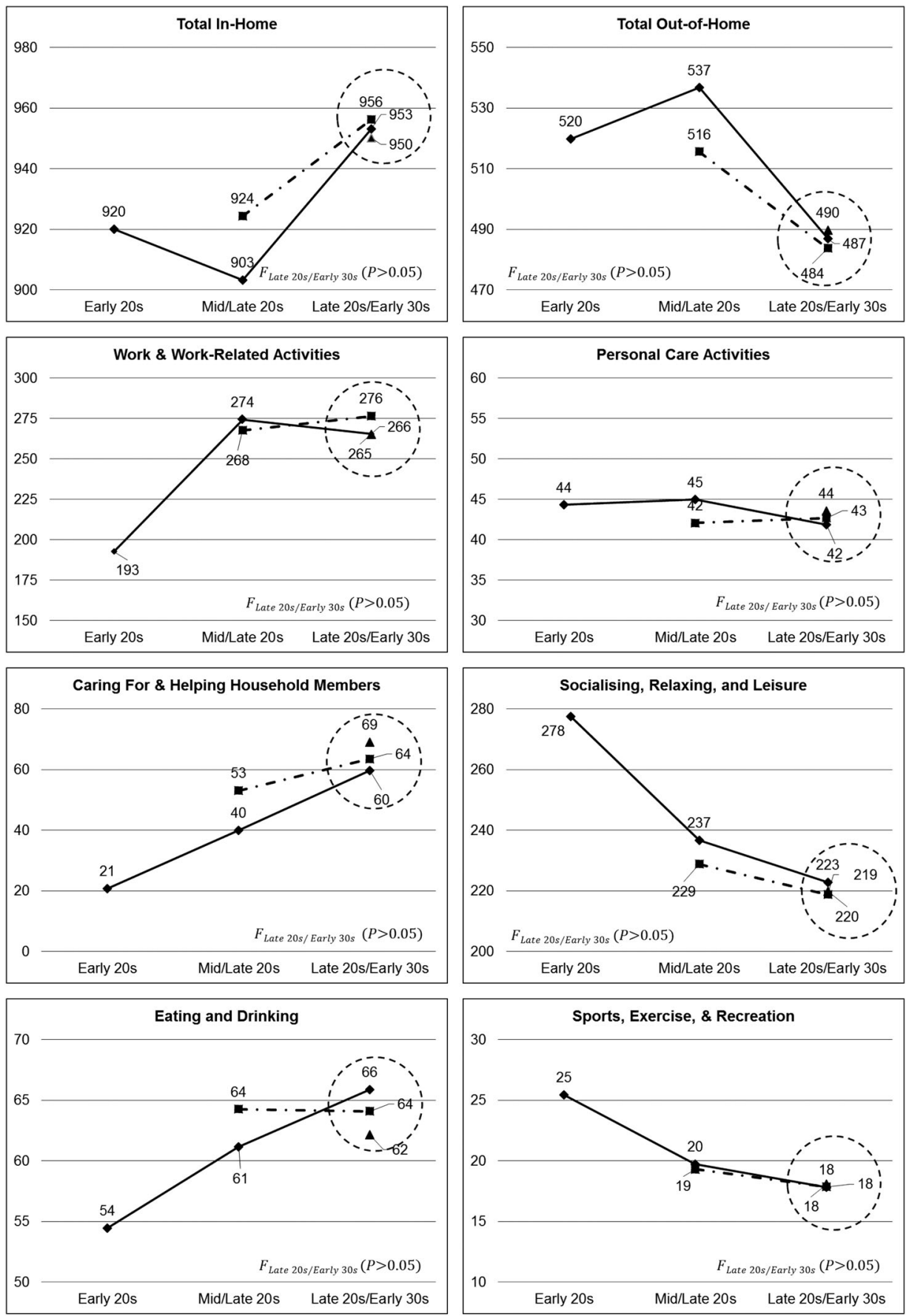

-GenX1: 1967-72 —a. GenX2: 1973-78 —Millennial: 1979-85

Figure 1. Evolution of time use patterns for different cohorts (in minutes). 

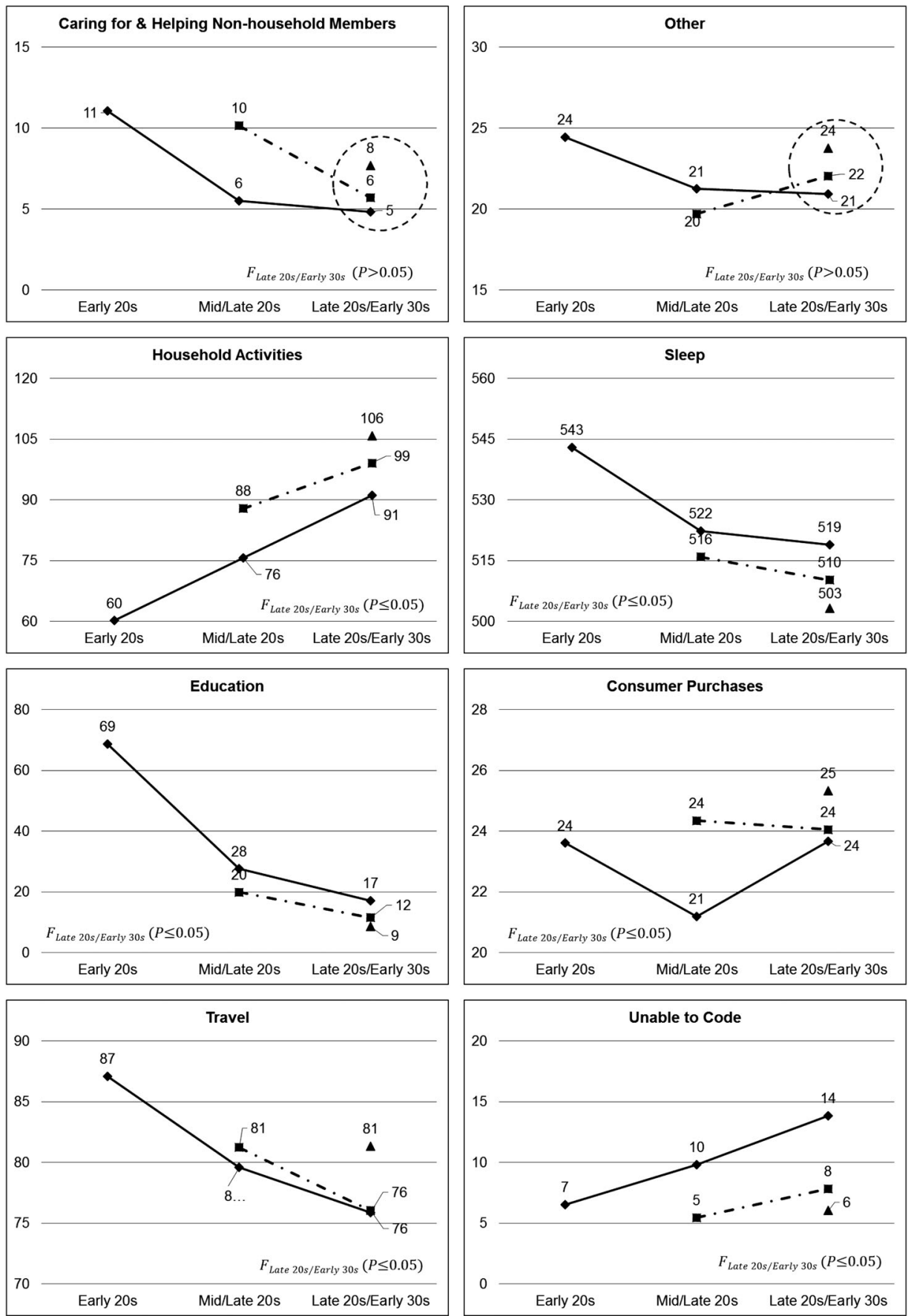

-GenX1: 1967-72 —a. GenX2: 1973-78 — Millennial: 1979-85

Figure 1. Continued 
with GenX individuals; however, the differences are not statistically significant, once again signifying a converging trend in activity-time use patterns.

A few notable exceptions can be observed wherein the average time use is significantly different across cohorts. Millennials in their late 20s/early 30s are found to spend significantly less time on household activities and more time sleeping. These differences are consistent with the notion that millennials have fewer household responsibilities than their GenX counterparts because of the lower prevalence of spousal and child presence. Also, Table 3 showed that millennials are enrolled in college to a greater degree than their predecessor GenX counterparts (Stilwell, 2014), and this is reflected in their significantly higher time allocation to education.

Significant differences across cohorts are also observed in time spent for consumer purchases and travel in the late 20 s/early 30 s age range. Although these differences are statistically significant, it is worth noting that the daily time allocations for these purposes are showing converging patterns; the trends clearly suggest that differences across cohorts, particularly between millennials and the immediately preceding GenX2, decrease in magnitude as individuals age into their late 20s/early 30s. The "unable to code" category is worthy of additional research; millennials are engaging in such activities (multitasking, activities not well-defined, and activities that individuals do not remember or wish to disclose) for a substantially longer duration than GenX individuals at similar age ranges. Lacking a convincing narrative as to why millennials might be more likely to forget activities, or be unable/unwilling to express what their activities are, it is conjectured that most of the difference involves multitasking activities that are difficult to code, which likely includes a large portion of technology use while other activities are being undertaken. Along those lines, it is possible that millennials, having grown up in an age of technology and multitasking (Silver, 2014), are prone to continuing and leveraging established habits and patterns of multitasking into their older adulthood.

Unfortunately, it is not possible to compare the cohorts at the starting point (i.e. when all generations were in their early 20s), due to the limitations of the timespan for which data are available. Based on research reported in the literature (e.g. Le Vine \& Jones, 2012; McDonald, 2015; Polzin et al., 2014), it appears that the millennials (young adults of today) are behaving quite differently than the young adults of prior generations. This implies that the millennials have different starting points in life; when they are in their early 20s, they are not behaving like GenX and Baby Boomers in their early 20s. However, despite having a different starting point, they seem to be settling into a rather similar end point once they age into their late 20s/early 30 s and begin to experience the more advanced lifecycle milestones of marriage, child-bearing, and labour force participation. Overall, the evidence shows that differences in activity-time use patterns diminish with age and those that appear to persist may be explained by differences in socioeconomic and demographic characteristics as well as period-specific effects such as the severe economic recession and rapid evolution of technology. These lingering differences may simply be reflective of the well-documented delay or lag in the occurrence of lifecycle events for millennials (Furstenberg, 2010; Lamberti, 2015; Pew Research Center, 2014; Taylor et al., 2012; Thompson, 2012), as opposed to any fundamental structural shift in attitudes, values, and perceptions relative to prior generations.

Table 4 presents a similar comparison for travel mode use patterns. The ATUS data set does not provide travel-related information in as much detail as the National Household 
Table 4. Evolution of mode use for different cohorts (duration in minutes/day).

\begin{tabular}{|c|c|c|c|c|c|}
\hline \multirow[b]{2}{*}{ Mode } & \multirow[b]{2}{*}{ Cohort (year of birth) } & \multicolumn{3}{|c|}{ Age-stage } & \multirow[b]{2}{*}{ Converging with age? } \\
\hline & & $\begin{array}{l}\text { Early } \\
20 s\end{array}$ & $\begin{array}{l}\text { Mid-/late } \\
\text { 20s }\end{array}$ & $\begin{array}{c}\text { Late } 20 \text { s/early } \\
30 \mathrm{~s}\end{array}$ & \\
\hline \multirow[t]{3}{*}{ Car driver (duration) } & GenX1 (1967-1972) & - & - & 60.7 & \multirow{3}{*}{$\begin{array}{l}\text { No, millennials slightly } \\
\text { lower }\end{array}$} \\
\hline & GenX2 (1973-1978) & - & 57.8 & 55.1 & \\
\hline & Millennials (1979-1985) & 52.8 & 53.1 & 53.1 & \\
\hline \multirow[t]{3}{*}{ Car driver (trips/day) } & GenX1 (1967-1972) & - & - & 3.44 & \multirow{3}{*}{$\begin{array}{l}\text { No, millennials slightly } \\
\text { lower }\end{array}$} \\
\hline & GenX2 (1973-1978) & - & 3.21 & 3.17 & \\
\hline & Millennials (1979-1985) & 3.18 & 3.05 & 2.94 & \\
\hline \multirow{3}{*}{$\begin{array}{l}\text { Car passenger } \\
\text { (duration) }\end{array}$} & GenX1 (1967-1972) & - & - & 11.4 & \multirow[t]{3}{*}{ Yes } \\
\hline & GenX2 (1973-1978) & - & 13.6 & 11.6 & \\
\hline & Millennials (1979-1985) & 20.8 & 13.0 & 11.4 & \\
\hline \multirow{3}{*}{$\begin{array}{l}\text { Car passenger (trips/ } \\
\text { day) }\end{array}$} & GenX1 (1967-1972) & - & - & 0.55 & \multirow[t]{3}{*}{ Yes } \\
\hline & GenX2 (1973-1978) & - & 0.64 & 0.56 & \\
\hline & Millennials (1979-1985) & 0.96 & 0.66 & 0.52 & \\
\hline \multirow{3}{*}{$\begin{array}{l}\text { Non-motorised } \\
\text { (duration) }\end{array}$} & GenX1 (1967-1972) & - & - & 3.0 & \multirow[t]{3}{*}{ Yes } \\
\hline & GenX2 (1973-1978) & - & 3.3 & 3.1 & \\
\hline & Millennials (1979-1985) & 5.2 & 4.9 & 3.3 & \\
\hline \multirow{3}{*}{$\begin{array}{l}\text { Non-motorised (trips/ } \\
\text { day) }\end{array}$} & GenX1 (1967-1972) & - & - & 0.34 & \multirow[t]{3}{*}{ Yes } \\
\hline & GenX2 (1973-1978) & - & 0.38 & 0.36 & \\
\hline & Millennials (1979-1985) & 0.58 & 0.43 & 0.35 & \\
\hline \multirow{3}{*}{$\begin{array}{l}\text { Public transit } \\
\text { (duration) }\end{array}$} & GenX1 (1967-1972) & - & - & 2.6 & \multirow[t]{3}{*}{ Yes } \\
\hline & GenX2 (1973-1978) & - & 2.9 & 2.9 & \\
\hline & Millennials (1979-1985) & 4.8 & 4.3 & 3.4 & \\
\hline \multirow{3}{*}{$\begin{array}{l}\text { Public transit (trips/ } \\
\text { day) }\end{array}$} & GenX1 (1967-1972) & - & - & 0.09 & \multirow[t]{3}{*}{ Yes } \\
\hline & GenX2 (1973-1978) & - & 0.09 & 0.09 & \\
\hline & Millennials (1979-1985) & 0.13 & 0.11 & 0.10 & \\
\hline \multirow[t]{3}{*}{ Other (duration) } & GenX1 (1967-1972) & - & - & 0.8 & \multirow[t]{3}{*}{ Small numbers } \\
\hline & GenX2 (1973-1978) & - & 0.9 & 0.6 & \\
\hline & Millennials (1979-1985) & 1.1 & 1.6 & 1.1 & \\
\hline \multirow[t]{3}{*}{ Other (trips/day) } & GenX1 (1967-1972) & - & - & 0.01 & \multirow[t]{3}{*}{ Small numbers } \\
\hline & GenX2 (1973-1978) & - & 0.02 & 0.01 & \\
\hline & Millennials (1979-1985) & 0.02 & 0.02 & 0.02 & \\
\hline \multirow{3}{*}{$\begin{array}{l}\text { Missing mode } \\
\text { (duration) }\end{array}$} & GenX1 (1967-1972) & - & - & 3.1 & \multirow{3}{*}{$\begin{array}{l}\text { No, millennials slightly } \\
\text { higher }\end{array}$} \\
\hline & GenX2 (1973-1978) & - & 2.7 & 2.8 & \\
\hline & Millennials (1979-1985) & 2.5 & 2.6 & 3.6 & \\
\hline \multirow{3}{*}{$\begin{array}{l}\text { Missing mode (trips/ } \\
\text { day) }\end{array}$} & GenX1 (1967-1972) & - & - & 0.18 & No, millennials slightly \\
\hline & GenX2 (1973-1978) & - & 0.18 & 0.19 & higher \\
\hline & Millennials (1979-1985) & 0.19 & 0.19 & 0.22 & \\
\hline
\end{tabular}

Note: The numbers in italics represent 'trip rates' as opposed to durations presented in non-italics.

Travel Survey. However, it does provide basic mode choice information for any activity that is classified as travel. The table shows time spent travelling by various modes and the trip rates by mode for the three cohorts of interest. Once again, it can be seen that millennials in their late 20s/early 30s are largely behaving like GenX1 and GenX2 cohorts when it comes to mode use patterns, especially in terms of travel as car passenger, by transit, or by non-motorised modes. However, a lingering difference remains in the level of car driving. There is plenty of evidence, as noted earlier in the paper, that millennials are somewhat more likely to shun cars and drive less. The data here support the literature; time spent travelling as a car driver held steady for millennials at 53 minutes even as they aged into their late 20s/early 30s. This is somewhat similar to that exhibited by GenX2 individuals who spent 55 minutes travelling as car drivers in their late 20s/early 30s, but quite different from that exhibited by GenX1 (older generation $\mathrm{X}$ ) individuals who spent, on average, 61 minutes travelling as car drivers at that age.

Thus, there is no clear evidence of convergence in the time allocation (or trip rate) for the car driver mode; millennials are persistently lower than their prior generation 
counterparts, although differences between younger GenX individuals (GenX2) and older millennials seem to be fading with age. It was also found that the millennial sample exhibits a higher prevalence of missing mode information, and the effects of these missing data on trends in the table are unclear. The notion that millennials may increasingly mirror the travel patterns exhibited by prior generations as they age is consistent with recent trends observed in VMT per capita. According to recent travel volume trends in the United States (covering the period after the 2012-2013 ATUS data), VMT per capita is rising and beginning to inch closer to the peak VMT per capita values seen in 2005 (Polzin, 2016; Short, 2015). This trend can be attributed to an increase in travel in more recent years across all age cohorts and demographic groups, including the millennials. While low fuel prices, disruptive transportation technologies (autonomous vehicle technologies; ride hailing companies such as Uber and Lyft), and a sustained economic recovery (i.e. period effects) may undoubtedly be contributing to the recent increase in VMT per capita, it may also be conjectured that millennials who have now entered their early/mid30s (i.e. aged beyond the stages covered in Tables 3 and 4) are starting to exhibit higher levels of travel similar to predecessor generations, thus leading to an increase in VMT per capita. Whether rising VMT per capita figures will ever match or exceed the levels seen in the United States at the peak in 2005 remains an open question and depends, at least in part, on how millennial travel patterns continue to evolve over time. If a lingering difference in millennial car travel persists, then it is unlikely that the peak levels of car travel seen in 2005 (in terms of VMT per capita) will be realised in the foreseeable future. On the other hand, if millennials increasingly mimic the behaviours of prior generations as they age and experience advanced lifecycle milestones (albeit with a lag), then VMT per capita will continue to rise in the absence of an economic shock or a transformative change in the built environment, rendering the existence of a "peak car/peak travel" phenomenon increasingly suspect.

\section{Focus on the younger millennials}

The analysis in the previous section provides insights into the ageing effects while controlling for cohort effects. The millennials considered in the previous section are the older millennials, those born between 1979 and 1985. As the youngest GenX (GenX2) individuals were born during 1973-1978, it is not all that surprising that the older millennials and the younger GenX2 group show similarities in activity-time use patterns. Although a number of surveys and studies define the millennial generation as that born beginning in the late 1970s, there are others who define the millennials as being born only after 1982 (Haughn, 2015). It may be argued that the technological service-based applications (apps) revolution really started only in the 1990s, and therefore it is the later millennials (those born in the 1990s and later) who would be truly different in their patterns. In an attempt to control for age effects, and better understand the activity-time use patterns of younger millennials relative to older millennials, an analysis was undertaken to compare time allocation patterns across cohorts while controlling for age effects. Table 5 presents a comparison of activity-time use patterns for:

(A) Generation X individuals born 1970-1976: 27-33 years old in ATUS 2003-2004

(B) Older millennials born 1979-1985: 27-33 years old in ATUS 2012-2013 
Table 5. Comparison of activity-time use patterns for different cohorts at the same age (minutes per day).

\begin{tabular}{|c|c|c|c|c|c|c|c|}
\hline Activity & $\begin{array}{l}\text { Born } 1970-1976 \\
\text { GenX at } \\
\text { age } 27-33 \\
\text { (data } 2003-2004 \text { ) } \\
\text { (A) }\end{array}$ & $\begin{array}{l}\text { Born } 1979-1985 \\
\text { Older Millens at } \\
\text { age } 27-33 \\
\text { (data 2012-2013) } \\
\text { (B) }\end{array}$ & $\begin{array}{c}t \text {-Test } \\
p \text {-value } \\
\text { (A) vs. (B) }\end{array}$ & $\begin{array}{c}\text { Born 1979-1985 } \\
\text { Older Millens at } \\
\text { age 18-24 } \\
\text { (data 2003-2004) } \\
\text { (C) }\end{array}$ & $\begin{array}{l}\text { Born } 1988-1994 \\
\text { Younger Millens at } \\
\text { age } 18-24 \\
\text { (data 2012-2013) } \\
\text { (D) }\end{array}$ & $\begin{array}{c}t \text {-Test } \\
p \text {-value } \\
\text { (C) vs. (D) }\end{array}$ & $\begin{array}{c}t \text {-Test } \\
p \text {-value } \\
\text { (B) vs. (C) }\end{array}$ \\
\hline Personal care (except sleep) & 42 & 42 & .95 & 44 & 46 & .55 & .07 \\
\hline Sleep & 506 & 519 & .01 & 543 & 556 & .19 & .00 \\
\hline Household activities & 94 & 91 & .10 & 60 & 54 & .18 & .00 \\
\hline Caring for household members & 59 & 60 & .55 & 21 & 22 & .36 & .00 \\
\hline Caring for non-HH members & 9 & 5 & .00 & 11 & 6 & .02 & .00 \\
\hline Work and work-related & 272 & 266 & .15 & 193 & 181 & .83 & .00 \\
\hline Education & 14 & 17 & .82 & 69 & 67 & .74 & .00 \\
\hline Consumer purchases & 26 & 24 & .00 & 24 & 18 & .00 & .35 \\
\hline Eating and drinking & 62 & 66 & .04 & 54 & 60 & .19 & .00 \\
\hline Social, relaxing, and leisure & 228 & 223 & .03 & 278 & 281 & .25 & .00 \\
\hline Sports, exercise, and recreation & 19 & 18 & .28 & 25 & 29 & .30 & .00 \\
\hline Unable to code & 6 & 14 & .00 & 7 & 19 & .00 & .00 \\
\hline Other & 20 & 21 & .32 & 24 & 25 & .48 & .44 \\
\hline Total in-home & 932 & 953 & .17 & 920 & 963 & .00 & .00 \\
\hline Total out-of-home & 508 & 487 & .17 & 520 & 477 & .00 & .00 \\
\hline Travel & 82 & 76 & .00 & 87 & 76 & .00 & .00 \\
\hline Car driver & 59 & 53 & .00 & 53 & 42 & .00 & .47 \\
\hline Car passenger & 12 & 11 & .02 & 21 & 20 & .03 & .00 \\
\hline Public transit & 3 & 3 & .72 & 5 & 5 & .30 & .21 \\
\hline Non-motorised & 3 & 3 & .10 & 5 & 5 & .54 & .01 \\
\hline Other & 1 & 1 & .64 & 1 & 1 & .71 & .92 \\
\hline Missing & 3 & 4 & .15 & 2 & 3 & .67 & .11 \\
\hline Sample size (unweighted) & 4198 & 2854 & - & 2443 & 1398 & - & - \\
\hline
\end{tabular}

Notes: Null hypothesis: $\mathrm{H}_{0} \rightarrow$ Means are equal. Cannot reject null hypothesis $(p>.05)$. Reject null hypothesis $(p \leq .05)$. 
(C) Older millennials born 1979-1985: 18-24 years old in ATUS 2003-2004

(D) Younger millennials born 1988-1994: 18-24 years old in ATUS 2012-2013

Comparing groups $\mathrm{A}$ and $\mathrm{B}$, it can be seen that older millennials and GenX individuals show both similarities and significant differences when they are 27-33 years of age. Equality of means cannot be rejected for time spent on personal care, household activities, caring for household members, work, education, sports and exercise, and travel by alternative modes. In addition, equality of means cannot be rejected for total time spent in-home and out-of-home. The takeaway is that older millennials show patterns of similarity with their GenX counterparts at 27-33 years of age, but there are lingering and statistically significant differences that have remained. Compared to GenX individuals at the same age, older millennials spend more time sleeping, eating and drinking, and multitasking (which would be categorised as "unable to code" in the ATUS data), and less time socialising/relaxing, and driving/riding in a car - somewhat consistent with the stereotype that they are lazy (Linn, 2014) and go nowhere (McDonald, 2015).

Comparing the older millennial cohort at age 18-24 years vs. when they are age 27-33 years (i.e. columns B and C), it can be seen that they have gone through the expected significant transformation with ageing (consistent with results presented in the last section). Most activity categories show statistically significant differences in durations, including total time spent in-home and out-of-home. Their time spent driving a car remains steady at 53 minutes, but their time spent as a car passenger drops (as expected with ageing) from 21 to 11 minutes. Comparing these observations with those of the preceding paragraph, it appears that as older millennials progress through life stages, they are becoming increasingly like their GenX counterparts at the same age, albeit with a few lingering statistically significant differences. Given that there are differences in socio-economic and demographic characteristics as shown in Table 3, it may be conjectured that the older millennials are converging to the patterns of GenX, but with a lag; in other words, older millennials are likely to mirror the patterns depicted by 27-33-year-old GenX individuals when they reach the age range of mid-/late 30 s. Given that millennials are choosing delayed marriage, child-bearing, and entry into the labour force, such a lag is expected, and differences in activity-time use patterns may actually be due to a "stage of life issue" (Linn, 2014) as opposed to any fundamental transformative shifts in attitudes and values. This remains, however, an open question worthy of further research as additional cross-sections of time use data become available: will millennials converge to patterns of prior generations, albeit with a lag as they reach various lifecycle milestones, or will lingering differences remain in millennial time use patterns (even after accounting for lifecycle stage) due to the technology revolution, the plethora of service-based applications, concerns about the economy, and fundamentally different lifestyle preferences and values (Sakaria \& Stehfest, 2013)?

The comparison between means in columns $C$ and $D$ suggests that older millennials and younger millennials were not very different in their time use patterns when both groups were young adults (18-24 years old). In comparing activity durations by purpose, it is found that the means are largely not (statistically) significantly different, except for a few activity categories, namely, caring for non-household members, consumer purchases, and activities unable to be coded (multitasking involving technology use). 
However, what is noteworthy is that the total durations of time spent in-home (and out-ofhome) are significantly different, with younger millennials spending more time in-home than their older counterparts in early adulthood. Time spent travelling is significantly different as well, with younger millennials spending considerably less time as a car driver. The similarity in total activity durations by purpose, but significant differences in total in-home and out-of-home (and travel) durations, clearly points to a location substitution effect where younger millennials are substituting out-of-home activity engagement with in-home activity participation.

The pairwise differences in time use allocation between cohorts are depicted further in Figure 2. In the figure, the light grey coloured bars refer to differences in time use between older millennials and GenX (at 27-33 years), while the dark grey coloured bars refer to differences in time use between younger and older millennials (at 18-24 years). It can be seen that the younger millennials (at 18-24 years) are pursuing activities in-home significantly more than the older millennials did when they were 18-24 years old. In other words, they are pursuing various activities to a similar degree, but at a different location - in-home - which is associated with reduced travel.

Figure 3 provides further insights into the trends that contribute to the large in-home duration difference between older and younger millennials (at 18-24 years). In the figure, the light grey coloured bars refer to differences in out-of-home durations by activity type while the dark grey coloured bars refer to differences in in-home durations. If the bars are in the positive territory $(\uparrow)$, it means that younger millennials are spending more time in the respective category; if the bars are in the negative territory $(\downarrow)$, then it means that older millennials are spending more time in the respective category. In general, the additional time spent in-home for younger millennials can be attributed to sleep, socialising-relaxation, work and looking-for-work, eating/drinking, and "unable to code" categories. It would appear that younger millennials are spending more leisure time at home, but they are also studying and working (or looking for work) more at home than the older millennials did when they were 18-24 years of age. Why are younger millennials spending more time at home than older millennials did in young adulthood? Is it because

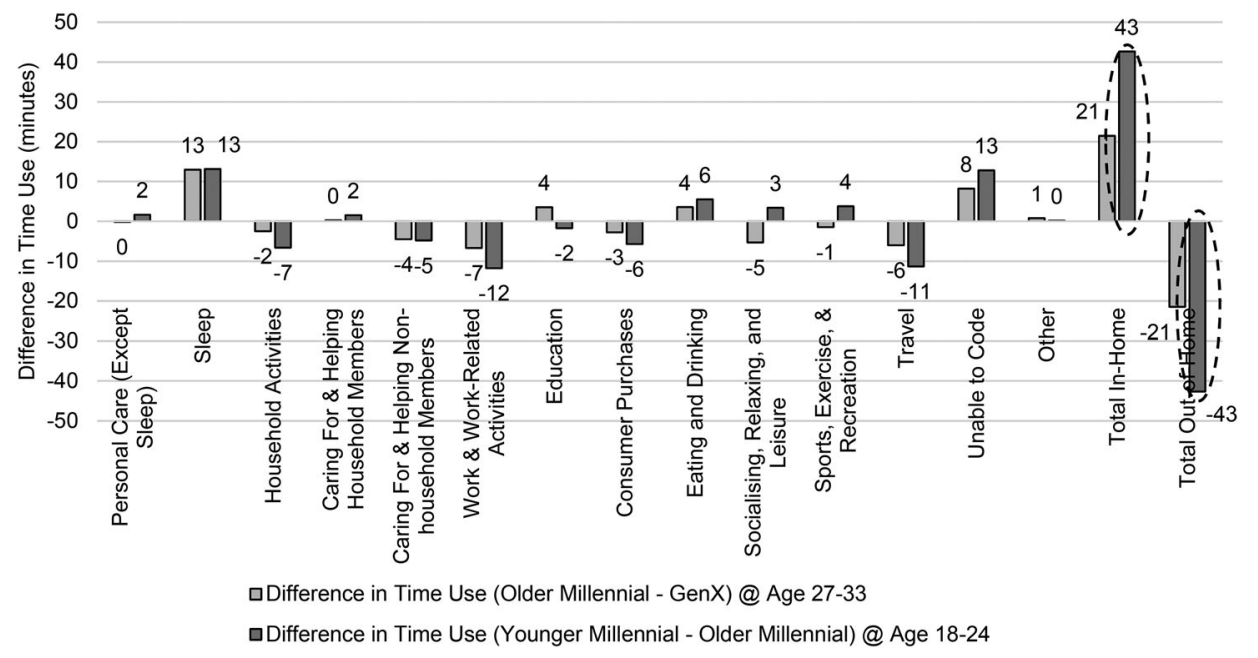

Figure 2. Differences in activity durations between cohorts (in minutes). 


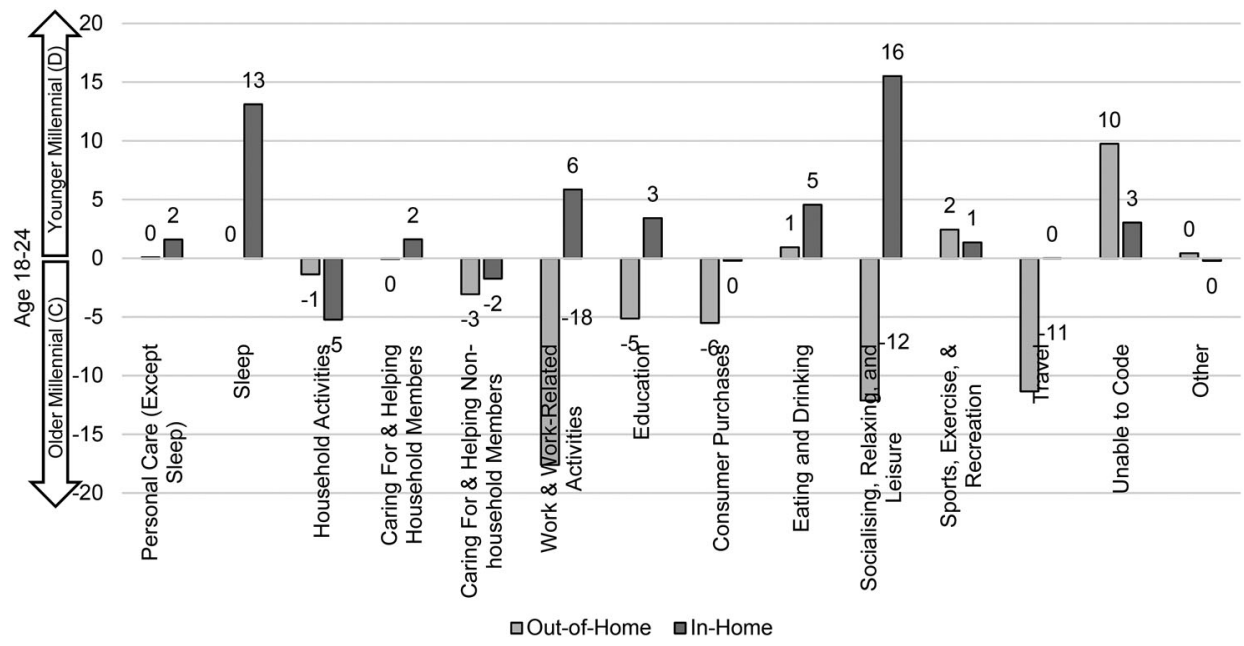

Figure 3. Differences in activity durations by location for millennial groups.

of period effects characterised by a post-recessionary era of tighter budgets and rapid evolution of technology and social media use, or is it because of fundamentally different lifestyle preferences and attitudes? As the older millennials were 18-24 years of age in 2003-2004 when the US economy was at its peak performance while the younger millennials were 18-24 years of age in 2012-2013 in a post-recessionary period, the reduced participation in out-of-home activities and car travel for the latter group is not surprising. Nevertheless, these are questions that remain subjects for future research as additional data on millennial behaviour become available. Regardless of the reasons underlying differences in time use patterns across cohorts at early adulthood (18-24 years of age), it does appear that the differences fade with age. This is demonstrated by the finding that differences in time use between older millennials and GenX individuals at the relatively older age of 27-33 years are smaller in magnitude than the differences between younger and older millennials in early adulthood (i.e. 18-24 years of age).

\section{Discussion and conclusions}

This paper presents detailed comparisons of travel and time use trends between the millennial generation and the preceding generation (Generation $\mathrm{X}$ ) with a view to determine whether the atypical travel patterns exhibited by the millennial generation (as documented in the literature) persist or fade as they age. The findings in this paper suggest that the much-discussed and written-about transformative changes that millennials may bring about in society are not likely to occur, although additional cross-sections of data are needed to draw definitive conclusions. The longitudinal trend analysis conducted using the American Time Use Survey in this paper shows that, as millennials age into their 30 s, they are increasingly exhibiting activity-time use patterns that resemble those of Generation $\mathrm{X}$ individuals when they were in their early 30 s. This finding is corroborated by Mui (2015), who notes that as millennials reach "delayed" milestones (marriage, parenthood) in their life, they are beginning to reevaluate their beliefs and display behavioural trends 
similar to those of previous generations. Nevertheless, a few differences in time use patterns remain even after controlling for age effects. Millennials are found to spend about 20 additional minutes, on average, at home and show reduced levels of driving compared to Generation X individuals at even the more advanced age of 27-33 years old. The extent to which these differences may be attributed to differences in socio-economic and demographic characteristics, the new reality brought on by the recession, fundamental shifts in attitudes, preferences, and values, and rapid evolution of technology and social media use, remains unclear. Unravelling the degree to which each of these factors contributes to differences in activity-time use patterns across generations is an effort worthy of further research that calls for the collection of additional data that specifically address "how and why" millennials participate in activities and travel the way they do.

The generation that depicts remarkably different patterns in activity location is the younger millennial cohort born between 1988 and 1994. In total, younger millennials 18-24 years old are spending 40 more minutes at home per day than the older millennials did when they were 18-24 years old. It is unclear whether younger millennials will also begin to converge to the activity-time use patterns of prior generations as they age, as the older millennials are. The statistics suggest that millennials have a different starting point at young adulthood, 18-24 years, in terms of their activity and travel choices, and these differences slowly fade as they age (as seen in Figure 1, and Tables 4 and 5). However, during the period that differences do exist, millennials drive less; this period of lower car ownership and vehicle use yields tangible benefits in terms of reduced VMT, energy consumption, and emissions. These benefits are likely to be substantial and are worthy of explicit recognition in transportation planning processes through a specific accounting of the activity location and travel choices of the millennial generation. The differences do fade (as shown in the ageing effects section of this paper) as the millennials enter their early 30s, and any differences that persist are closely aligned with differences in socio-economic and demographic characteristics associated with delayed lifecycle milestones experienced by millennials (delayed marriage, child-bearing, and entry into labour force). In other words, after accounting for differences in socio-economic and demographic characteristics, and period-specific effects (state of the economy, fuel prices, technology and social media, and disruptive mobility services), there do not appear to be many cohort-specific effects (lifestyle preferences, attitudes, and values) contributing to differences in activity-time use patterns; if there were such effects, then differences in activity-time use patterns would not fade to the degree that they do.

The contribution of ICT to reduced levels of mobility remains unclear. Unfortunately, the ATUS data do not provide information on ICT use at a sufficient level of detail, and there may be missing ICT use when such use is secondary to a primary activity. Enhancements in the recording of ICT-related activities and secondary/tertiary activities in the ATUS data would help unravel the patterns of complementarity and substitution that may exist between out-of-home activity-travel engagement and ICT use. A preliminary analysis of ICT-related time expenditures for select activity codes in the ATUS data shows that older millennials significantly reduce ICT time use as they age and become quite similar to Generation X in their early 30s. Younger millennials, however, are found to devote significantly more time to ICT use than older millennials in early adulthood (18-24 years of age). Additional cross-sections of data are needed to determine whether such differences will persist or fade with age. There is, however, little evidence to suggest that technology is 
substituting for travel in any significant way. In a study that is now somewhat dated, Robinson, Kestnbaum, Neustadtl, and Alvarez (2000) found no significant or consistent evidence of time displacement from mass media use or social activities as a result of internet or computer use. Blumenberg et al. (2012) found that web use does not substitute for travel; further, they report that a higher level of web use is associated with increased person miles of travel across all age categories, presumably because web use, auto access, and personal travel are all positively associated with education and income. Similarly, Mokhtarian (2009) discusses a number of mechanisms accounting for what, so far, has overall been a complementary relationship between telecommunications and travel. While there is clear evidence that younger millennials use technology more than prior generations (Pew Research Center, 2015), there is a lack of confirmatory evidence on the evolving relationship between travel and ICT use.

Overall, the analysis in this paper shows that millennials, as they age, are exhibiting behaviours that mimic the activity-time use patterns of prior generations, and therefore transportation planning professionals should not assume that travel demand or VMT will cease to grow into the future. Indeed, recent evidence shows that, in the United States, trends in VMT depict an upward trajectory both in the aggregate and on a percapita basis (Polzin, 2016), challenging the notion of "peak car/peak travel" that has been the subject of recent research (Goodwin \& Van Dender, 2013; Stokes, 2013; van Wee, 2015). Aggregate VMT reached new highs in 2015, and VMT per capita inched closer to the peak values seen in 2005-2006, clearly indicating that the nosedive in VMT between 2007 and 2013 may be largely attributed to the effects of the recession as opposed to any fundamental shifts in behaviours, attitudes, and lifestyles.

Based on the trends reported in this paper, transportation planning professionals should not expect a fundamental shift in travel demand in the future. Millennials are often touted as the generation that will bring about transformative changes in the transport sector. Their adoption of technology-based services, the sharing economy, the internet of things, and alternative modes of transportation is seen as the harbinger of a turning point in transportation that is characterised by lower levels of personal car ownership and use. The longitudinal analysis in this paper suggests that, as young adults, millennials are behaving differently, but the differences dampen with age, and are likely to fade further as millennials experience advanced lifecycle milestones. Given these findings, transportation planning efforts should aim to design urban spaces and modal alternatives that leverage and sustain the differences seen in young adulthood into the latter stages of life as much as possible. This involves a thoughtful design of urban spaces where young adults experience and enjoy a sense of place consistent with the needs of a maturing household. Green spaces for children to play, urban gardens, safe neighbourhoods to walk and bicycle, a variety of affordable housing options that meet the demands of a growing family, highquality educational institutions, and retail and recreational opportunities that are easily accessible are likely to constitute a built environment that retains millennials and sustains their less-car-oriented activity-travel patterns over longer periods of time, even after they have married and had children. In addition, even though millennials may age to be increasingly similar to their predecessor generations, there will always be new young adults in subsequent generations (Generation $Z$ and beyond) that may exhibit traits similar to the millennials of today, and/or distinctive new traits of their own. Continuously leveraging the unique behavioural characteristics of young adults through a targeted set 
of strategies may offer substantial gains in advancing sustainable transportation patterns, and bring about the fundamental shifts in behaviours and attitudes needed to avoid the proverbial inevitability of the repeat of history dominated by sprawl and auto-oriented mobility.

In the transport modelling arena, activity-travel demand forecasting models supporting transportation planning processes often use income and vehicle ownership as segmentation variables (to recognise differences in behavioural patterns across socio-economic segments). Given the unique traits of millennials in their early adult years, and the desire to sustain their traits over an extended period of time, it may behoove the profession to consider using the generational cohort as a segmentation variable instead of or in addition to existing segmentation variables. By isolating and modelling the travel patterns of each generation separately over time, it will be possible to plan transport infrastructure investments, design modal options, and formulate land use policies that cater to the needs of the disparate generations.

\section{Acknowledgements}

The authors gratefully acknowledge the valuable comments and suggestions of four anonymous referees that greatly contributed to improving the paper. The authors thank Dr Daehyun You for assistance with data preparation. The authors are responsible, however, for any errors or omissions.

\section{Disclosure statement}

No potential conflict of interest was reported by the authors.

\section{ORCID}

Venu M. Garikapati (D) http://orcid.org/0000-0003-1603-1883

Ram M. Pendyala (i) http://orcid.org/0000-0002-1552-9447

Eric A. Morris (D) http://orcid.org/0000-0001-8690-6644

Patricia L. Mokhtarian (D) http://orcid.org/0000-0001-7104-499X

\section{References}

Badger, E. (2014). The many reasons millennials are shunning cars. Retrieved July 25, 2015, from http:// www.washingtonpost.com/blogs/wonkblog/wp/2014/10/14/the-many-reasons-millennials-areshunning-cars/

Biro, M. M. (2014). Reconsidering millennials: They're not that different from you. Retrieved July 26, 2015, from http://www.forbes.com/sites/meghanbiro/2014/09/05/reconsidering-millennialstheyre-not-that-different-from-you/

Blumenberg, E. (2009). Moving in and moving around: Immigrants, travel behavior, and implications for transport policy. Transportation Letters, 1(2), 169-180.

Blumenberg, E., Taylor, B. D., Smart, M., Ralph, K., Wander, M., \& Brumbagh, S. (2012). What's youth got to do with it? Exploring the travel behavior of teens and young adults. Los Angeles: Institute of Transportation Studies, University of California at Los Angeles. Retrieved July 25, 2015, from http://www.escholarship.org/uc/item/9c14p6d5

Buchholz, T., \& Buchholz, V. (2012). The go-nowhere generation. Retrieved July 25, 2015, from http:// www.nytimes.com/2012/03/11/opinion/sunday/the-go-nowhere-generation.html 
The Council of Economic Advisors. (2014). 15 economic facts about millennials. Retrieved July 24, 2015, from https://www.whitehouse.gov/sites/default/files/docs/millennials_report.pdf

Davis, B., Dutzik, T., \& Baxandall, P. (2012). Transportation and the new generation. Retrieved July 25, 2015, from http://www.ospirg.org/sites/pirg/files/reports/Transportation\%20\%26\%20the\%20New \%20Generation.pdf

Delbosc, A., \& Currie, G. (2013). Causes of youth licensing decline: A synthesis of evidence. Transport Reviews, 33(3), 271-290.

Dutzik, T., Inglis, J., \& Baxandall, P. (2014). Millennials in motion: Changing travel habits of young Americans and the implications for public policy, U.S. PIRG education fund and frontier group. Retrieved August 2, 2015, from http://www.uspirg.org/sites/pirg/files/reports/Millennials\%20in\% 20Motion\%20USPIRG.pdf

Furstenberg, Jr., F. F. (2010). On a new schedule: Transitions to adulthood and family change. The Future of Children, 20(1), 67-87.

Goodwin, P., \& Van Dender, K. (2013). "Peak car" - themes and issues. Transport Reviews, 33(3), 243254.

Guay, M. W. (2015). How millennials are redefining the American dream. Retrieved July 30, 2015, from http://www.huffingtonpost.com/mark-w-guay/how-millennials-are-redef_1_b_7092990.html

Haughn, M. (2015). Millennials (millennial generation). Retrieved July 1, 2015, from http://www.whatis. techtarget.com/definition/millennials-millennial-generation

Hudson, K. (2015). Generation Y prefers suburban home over city condo. Retrieved July 31, 2015, from http://www.wsj.com/articles/millennials-prefer-single-family-homes-in-the-suburbs-1421896797

Jaffe, E. (2015). The clearest explanation yet for why millennials are driving less. Retrieved July 31, 2015, from http://www.citylab.com/commute/2015/07/the-clearest-explanation-yet-for-why-millennialsare-driving-less/398366/

Kuhnimhof, T., Armoogum, J., Buehler, R., Dargay, J., Denstadli, J. M., \& Yamamoto, T. (2012). Men shape a downward trend in car use among young adults - evidence from six industrialized countries. Transport Reviews, 32(6), 761-779.

Lamberti, P. (2015). Millennials just aren't that into starting families; is that such a bad thing? Retrieved July 29, 2015, from http://www.moneyunder30.com/millenials-waiting-to-start-a-family

Leanne, M. L., \& Brett, D. L. (2015). Gen Y and housing: What they want and where they want it. Washington, DC: Urban Land Institute. Retrieved July 25, 2015, from http://www.uli.org/wpcontent/uploads/ULI-Documents/Gen-Y-and-Housing.pdf

Le Vine, S., \& Jones, P. (2012). On the move: Making sense of car and train travel trends in Britain. London: RAC Foundation.

Le Vine, S., Latinopoulos, C., \& Polak, J. (2014). Establishing the links between online activity and car use: Evidence from a combined travel diary and online-activity pseudodiary data set. Transportation Research Record: Journal of the Transportation Research Board, 2405, 68-77.

Linn, A. (2014). Millennials: Lazy, entitled - or maybe just young. Retrieved July 29, 2015, from http:// www.today.com/money/millennials-lazy-entitled-or-maybe-just-young-2D79664367

Litman, T. (2006). Changing transportation trends and their implications for transport planning. Paper presented at the 85th Transportation Research Board Annual Meeting, Washington, DC.

Logan, G. (2014). Millennials' influence on new home demand. Retrieved July 25, 2015, from http:// www.rclco.com/advisory-millennials-real-estate

Lutz, A. (2014). Millennials are completely redefining what it means to own something. Retrieved July 30, 2015, from http://www.businessinsider.com/millennials-rent-instead-of-buy-2014-9

Lyons, G. (2015). Transport's digital age transition. Journal of Transportation and Land Use, 8(2), 1-19. Machado, A. (2014). How millennials are changing travel. Retrieved July 30, 2015, from http://www. theatlantic.com/international/archive/2014/06/how-millennials-are-changing-international-travel/ 373007/

Martin, S. P., Astone, N. M., \& Peters, H. E. (2014). Fewer marriages, more divergence: Marriage projections for millennials to age 40. Washington, DC: Urban Institute. Retrieved September 4, 2015, from http://www.urban.org/sites/default/files/alfresco/publication-pdfs/413110-Fewer-Marriages-MoreDivergence-Marriage-Projections-for-Millennials-to-Age-.PDF 
McDonald, N. C. (2015). Are millennials really the "go-nowhere" generation? Journal of the American Planning Association, 81(2), 90-103.

Millard-Ball, A., \& Schipper, L. (2011). Are we reaching peak travel? Trends in passenger transport in eight industrialized countries. Transport Reviews, 31(3), 357-378.

Mokhtarian, P. (2009). If telecommunication is such a good substitute for travel, why does congestion continue to get worse? Transportation Letters, 1(1), 1-17.

Mui, Y. Q. (2015). I'm a millennial with a minivan, and I feel pretty great about it. Retrieved August 11, 2015, from http://www.washingtonpost.com/news/wonkblog/wp/2015/08/07/im-a-millennialwith-a-minivan-and-i-feel-pretty-great-about-it/

Nielsen. (2014). Millennials prefer cities to suburbs, subways to driveways. Retrieved July 31, 2015, from http://www.nielsen.com/us/en/insights/news/2014/millennials-prefer-cities-to-suburbs-subwaysto-driveways.html

O'Connell, C. (2015). How millennials define frugality differently. Retrieved July 25, 2015, from http://www.money.usnews.com/money/the-frugal-shopper/2015/06/05/how-millennials-definefrugality-differently

Pew Research Center. (2014). Comparing millennials to other generations. Retrieved July 25, 2015, from http://www.pewsocialtrends.org/2015/03/19/comparing-millennials-to-other-generations/

Pew Research Center. (2015). This year, millennials will overtake baby boomers. Retrieved July 25, 2015, from http://www.pewresearch.org/fact-tank/2015/01/16/this-year-millennials-will-overtake-babyboomers/

Polzin, S. E. (2016). So much for peak VMT. Planetizen Blog Post. Retrieved May 25, 2016, from http:// www.planetizen.com/node/84877/so-much-peak-vmt

Polzin, S. E., Chu, X., \& Godfrey, J. (2014). The impact of millennials' travel behavior on future personal vehicle travel. Energy Strategy Reviews, 5, 59-65.

Robinson, J. P., Kestnbaum, M., Neustadtl, A., \& Alvarez, A. (2000). Mass media use and social life among internet users. Social Science Computer Review, 18(4), 490-501.

Rossenfeld, C. (2015). Urban burbs are here to stay. Retrieved July 25, 2015, from http://www.globest. com/blogs/counterculture/colliers/Urban-Burbs-Are-Here-to-Stay-358123-1.html

Sakaria, N., \& Stehfest, N. (2013). Millennials and mobility: Understanding the millennial mindset and new opportunities for transit providers (No. Task 17, TCRP Project J-11). Retrieved July 29, 2015, from http://www.onlinepubs.trb.org/onlinepubs/tcrp/tcrp_w61.pdf

Short, D. (2015). Vehicle miles traveled: A look at our evolving behavior. Retrieved August 28, 2015, from http://www.advisorperspectives.com/dshort/updates/DOT-Miles-Traveled.php

Silver, S. (2014). With tablets and TV, millennials love multitasking. Retrieved July 29, 2015, from http:// www.technologytell.com/entertainment/46326/tablets-tv-millennials-love-multitasking/

Sivak, M. (2013). Has motorization in the U.S. peaked (Report No. UMTRI-2013-17) UMTRI 2013-20. Retrieved July 29, 2015, from http://www.deepblue.lib.umich.edu/bitstream/handle/2027.42/ 98098/102947.pdf?sequence=1\&isAllowed $=y$

Sivak, M., \& Schoettle, B. (2011). Recent changes in the age composition of U.S. drivers: Implications for the extent, safety, and environmental consequences of personal transportation. Traffic Injury Prevention, 12, 588-592.

Sivak, M., \& Schoettle, B. (2012). Recent changes in the age composition of drivers in 15 countries. Traffic Injury Prevention, 13, 126-132.

Stilwell, V. (2014). Millennials most-educated U.S. age group after downturn: Economy. Retrieved July 24, 2015, from http://www.bloomberg.com/news/articles/2014-10-08/millennials-become-mosteducated-u-s-age-group-due-to-recession

Stokes, G. (2012). Has car use per person peaked? Age, gender and car use. Transport Statistics User Group Seminar, London. Retrieved May 20, 2016, from http://www.gordonstokes.co.uk/ transport/peak_car_2012.pdf

Stokes, G. (2013). The prospects for future levels of car access and use. Transport Reviews, 33(3), 360375.

Taylor, P., Parker, K., Kochhar, R., Fry, R., Funk, C., Patten, E., \& Motel, S. (2012). Young, underemployed, and optimistic: Coming of age, slowly, in a tough economy. Washington, DC: Pew Research Center. 
Retrieved July 25, 2015, from http://www.pewsocialtrends.org/files/2012/02/young-under employed-and-optimistic.pdf

Thompson, D. (2012). Adulthood, delayed: What has the recession done to millennials? Retrieved July 25, 2015, from http://www.theatlantic.com/business/archive/2012/02/adulthood-delayed-whathas-the-recession-done-to-millennials/252913/

Walker, A. (2015). Millennials will live in cities unlike anything we've ever seen before. Retrieved July 25 , 2015, from http://www.gizmodo.com/millennials-will-live-in-cities-unlike-anything-weve-se1716074100

van Wee, B. (2015). Peak car: The first signs of a shift towards ICT-based activities replacing travel? A discussion paper. Transport Policy, 42, 1-3.

Wester, L. (2015). Zipcar annual millennial survey. Retrieved July 28, 2015, from http://www.zipcar. com/press/releases/2015millennials

zipcar. (2015). Millennial is a state of mind - Zipcar 2015 millennial survey results. Retrieved July 25, 2015, from http://www.slideshare.net/Zipcar_PR/zipcar2015-millennialmind-slideshare?related=1 